\title{
MAIANTHEMUM MEXICANUM (LILIACEAE) \\ UNA NUEVA ESPECIE DE DURANGO, MEXICO
}

\author{
Abel Garcia-Arevalo' \\ CIIDIR Unidad Durango \\ Instituto Politécnico Nacional \\ Apdo. Postal 738 \\ 34000 Durango, Dgo. México
}

\section{RESUMEN}

Se describe Maianthemum mexicanum sp. nov., del sur del estado de Durango, de bosque propio de clima templado. La nueva especie está relacionada con $M$. racemosum (L.) Link, de la cual se distingue por las características de la inflorescencia.

\section{ABSTRACT}

Maianthemum mexicanum sp. nov., is described from the temperate forest of southern Durango state. The new species is related to $M$. racemosum (L.) Link, but differs in characteristics of the inflorescence.

Maianthemum mexicanum A. García-Arévalo, sp. nov. (Fig. 1)

Herba terrestris, usque ad $60 \mathrm{~cm}$ alta, erecta; caulis simplex, striatus; folia sessilia vel breviter petiolata, ovato-elliptica; inflorescentia paniculata, usque ad $6 \mathrm{~cm}$ longa, breviter ramosa; petali usque ad $1 \mathrm{~mm}$ longi, $0.4-0.7 \mathrm{~mm}$ lati; antherae $0.5-1 \mathrm{~mm}$ longae; stylus 0.1-0.4 mm longus; fructus sphaericus $5-7 \mathrm{~mm}$ diametro.

Hierba terrestre de 31-60 cm de alto. Raíces a lo largo del rizoma, 4 a 7 por entrenudo. Rizoma constituído de uni simpodio bifurcado, entrenudos cortamente cilíndricos a claviformes, de $0.3-1 \mathrm{~cm}$ de largo y 0.3 a $0.8 \mathrm{~cm}$ de ancho, renuevos laterales hasta 4; base del tallo con 3-4 vainas foliares de hasta $9 \mathrm{~cm}$ de longitud. Tallo erecto, simple, estriado, en zigzag, glabro o con pequeños tricomas cónicos translúcidos esparcidos sobre las costillas. Hojas 6 a 10, sésiles a cortamente pecioladas, lámina de la hoja ovado-elíptica, de $6.5-13 \mathrm{~cm}$ de longitud por $2-5.3 \mathrm{~cm}$ de ancho, ápice acuminado, base redondeada a atenuada, margen denticulado, haz de la hoja verde, envés glauco, ambas superficies de la hoja glabras. Inflorescencia una panícula alargada, difusamente ramificada en la madurez, con ca. 110 flores, eje principal hasta de $6 \mathrm{~cm}$ de largo, ejes secundarios cortos, menores de $1 \mathrm{~cm}$, con pubescencia de tricomas cónicos translúcidos, con 4-10 flores blanco

1 Dirección actual: Instituto de Ecología, A.C., Apdo. Postal 632, 34000 Durango, Dgo. México. 
Acta Botánica Mexicana (1992), 17:19-21
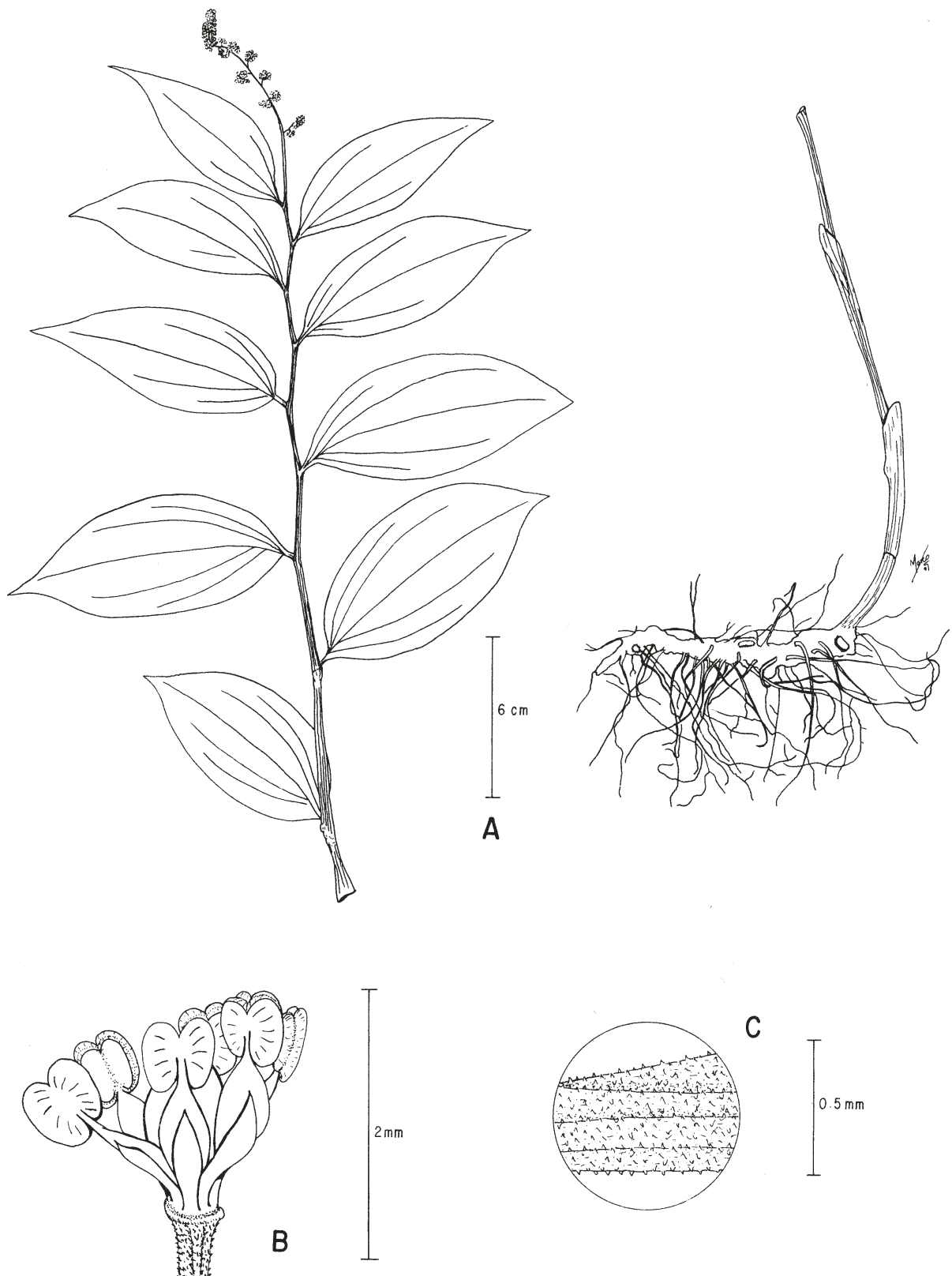

Fig. 1. Maianthemum mexicanum. A. Aspecto general de la planta y rizoma; B. Flor; C. Detalle de la pubescencia del pedicelo. 
amarillentas. Flores trímeras; pedicelos de 0.7-1.5 mm de largo por 0.3-0.5 de ancho generalmente con pequeños tricomas cónicos; perianto poco conspicuo, los tépalos ascendentes hasta de $1 \mathrm{~mm}$ de longitud por 0.4-0.7 mm de ancho; estambres insertos en la base de los tépalos, filamento petaloide a subpetaloide de $1.5-2.5 \mathrm{~mm}$ de longitud; anteras de 0.5-1 $\mathrm{mm}$ de longitud; ovario de 0.8-1.1 $\mathrm{mm}$ de longitud por 0.8-1.2 $\mathrm{mm}$ de ancho, estilo de 0.1-0.4 mm de longitud, estigma diminuto trilobado; fruto esférico, de 5$7 \mathrm{~mm}$ de diámetro, café rojizo en la madurez.

TIPO: México, Durango, Predio Las Bayas de la Universidad Juárez del Estado de Durango, arroyo La Tecolota, municipio de Durango, ladera húmeda con bosque de Pseudotsuga-Abies-Quercus. Alt. 2800 m. 16-VII-1991, A. Garcia y S. Acevedo 1008 (Holotipo: CIIDIR, isotipos a distribuirse).

Material adicional examinado: México, Durango, Predio Las Bayas de la Universidad Juárez del Estado de Durango, ladera húmeda con bosque de Pseudotsuga-Abies. Alt. 2850 m. 15-VII-1990. A. García con S. González y S. Acevedo 507 (CIIDIR).

Maianthemum mexicanum, de acuerdo con la revisión de LaFrankie (1986) para el género y considerando la presencia de flores trímeras, se ubica dentro del grupo Maianthemum sensu lato, anteriormente Smilacina. La nueva especie está relacionada con $M$. racemosum (L.) Link, sin embargo, el tipo de inflorescencia separa a ambas especies. En $M$. mexicanum se presenta una panícula alargada y diminutamente ramificada, con ejes secundarios menores de $1 \mathrm{~cm}$, y en $M$. racemosum la panícula es de forma piramidal, con ejes secundarios mayores de $1 \mathrm{~cm}$.

La distribución conocida para el género Maianthemum para el Continente Americano antes de las colectas aquí registradas, marca una notable disyunción en México entre las especies norteamericanas y mesoamericanas. M. mexicanum funge como eslabón del género entre dichas áreas geográficas.

\section{AGRADECIMIENTOS}

Se agradece a la Dra. Socorro González Elizondo, la revisión crítica y sugerencias al manuscrito y al Sr. Saturnino Acevedo por su colaboración en la colecta en campo de Maianthemum mexicanum.

\section{LITERATURA CITADA}

La Frankie, J.V. 1986. Morphology and taxonomy of the New World species of Maianthemum (Liliaceae). J. Arnold. Arbor. 67: 371-439. 